\title{
Interaction of Wyoming Bentonite and Grimsel Granodiorite in high temperature EBS experiments
}

\author{
SAUER, K.B ${ }^{1 *}$, Rock, M.J. ${ }^{1}$, CAPORUSCIO, F.A. ${ }^{1}$, \\ TELFEYAN $^{1}$, K.C., MATTEO, E.N. ${ }^{2}$
}

${ }^{1}$ Los Alamos National Laboratory, *sauer@lanl.gov

${ }^{2}$ Sandia National Laboratories

The United States Spent Fuel and Waste Disposition Campaign is conducting exploratory research to assess the feasability of a crystalline repository with thermal limits above $100^{\circ} \mathrm{C}$. We present here a lab-scale, experimental study that explores the mineralogical and geochemical changes in the bentonite engineered barrier system in contact with crystalline rock at higher temperatures that may be relevant to an increased thermal limit.

Six hydrothermal experiments were conducted with Wyoming Bentonite in a crystalline rock environment, simulated by including Grimsel Granodiorite (Grimsel Test Site) and synthetic Grimsel groundwater brine. One experiment included a cured chip of Ordinary Portland Cement. Reactions were conducted at $250^{\circ} \mathrm{C}$ and 150 bar for six to eight weeks at water:rock ratios of 9-11:1. Reaction products were evaluated post experiment with X-ray diffraction, and electron microprobe/microscopy.

Mineralogical changes include dissolution of precursor clinoptilolite, increase in smectite abundance, and quartz precipitation. Feldspars display dissolution textures, likely indicating alteration of feldspar to clay. Alteration of smectite to illite was not detected in any experiment. Montmorillonite experienced significant particle-size reduction to form a gel composed of bentonite colloids. Minor calcium silica hydrate phases (e.g., tobermorite) were detected in SEM images. The inclusion of cement resulted in slightly higher solution $\mathrm{pH}$ and the formation of zeolite minerals (e.g., analcime) next the cement chip surface.

These experimental results highlight mineral reactions that may be of importance to repository performance and the influence of bulk chemistry on bentonite reactions. Alteration of smectite to non-swelling phases (e.g., illite) was not observed in the reaction products, likely due to the low availability of potassium. Bentonite gel formation indicates that colloid-facilitated transport of radionuclides may be a concern in the crystalline environment. These results may help understand long-term, full-scale repository experiments as well as inform modelling studies of high temperature scenarios. 